\title{
CARACTERÍSTICAS FÍSICO-QUÍMICAS DA CASCA DO MARACUJÁ AMARELO EM DIFERENTES ESTÁDIOS DE MATURAÇÃO
}

\author{
CARLAAPARECIDAREOLON* \\ GILBERTO COSTABRAGA** \\ ARIANE BUSCH SALIBE***
}

\begin{abstract}
Este trabalho teve como objetivo avaliar a interferência do estádio de maturação do maracujá amarelo sobre as características físicas, químicas e minerais de sua casca. Foram testados três estádios de maturação do fruto conforme a coloração da casca: Estádio 1 - coloração da superfície da casca $100 \%$ verde; Estádio 2 - casca verde-amarela (50\% verde e 50\% amarela); Estádio 3 - casca 100\% amarela. Os componentes físico-químicos mensurados foram: rendimento de casca, matéria seca, cinzas, lipídios totais, proteínas, carboidratos totais e não redutores e pectinas totais. Os componentes minerais determinados foram: cálcio, cobre, ferro, manganês, potássio, magnésio, zinco e fósforo. Aplicou-se delineamento inteiramente ao acaso e quatro repetições para cada estádio de maturação do maracujá. Aos resultados foram aplicados Análise de Variância, teste $\mathrm{F}$ e teste Tukey de comparação entre médias $(p<0,05)$. Houve diminuição significativa no conteúdo de pectinas totais com a maturação do maracujá amarelo, variando de 28,51 a 20,69 g $100 \mathrm{~g}^{-1}$ (redução de $27,43 \%)$. Os resultados revelaram também reduções significativas nos teores de proteínas e carboidratos redutores. Não houve efeito da maturação do fruto sobre os minerais, nem alteração no teor de lipídios e seus valores revelaram matériaprima vegetal com baixo valor calórico. O ferro, o cálcio e o potássio foram os elementos de maior concentração e o cobre e o fósforo os de menor concentração na casca do maracujá amarelo. O ferro e o manganês foram os elementos minerais da casca mais expressivos para a dieta de adultos.
\end{abstract}

PALAVRAS-CHAVE: Passiflora edulis f. flavicarpa; PECTINA; MINERAIS; VALOR NUTRICIONAL.

* Mestranda em Agronomia, Programa de Pós-Graduação em Agronomia, Centro de Ciências Agrárias, Universidade Estadual do Oeste do Paraná (UNIOESTE), Campus de Marechal Cândido Rondon, PR (e-mail: carlareolon@yahoo.com.br).

** Professor, Doutor em Tecnologia de Produtos Agropecuários, Centro de Ciências Agrárias, UNIOESTE, Marechal Cândido Rondon, PR (e-mail: gbraga@unioeste.br).

*** Professora Doutora em Fruticultura, Centro de Ciências Agrárias, UNIOESTE, Marechal Cândido Rondon, PR (e-mail: absalibe@ig.com.br). 


\section{INTRODUÇÃO}

O maracujá amarelo (Passiflora edulis f. flavicarpa), fruto de clima tropical, é muito apreciado pelo seu suco, sendo o Brasil o maior produtor e o maior consumidor mundial dessa fruta. Em 2004, foram colhidas cerca de 490 mil toneladas de maracujá amarelo, com destaques para os Estados da Bahia, com 114 mil toneladas e do Espírito Santo, com 81 mil toneladas (AGRIANUAL, 2007).

A casca do maracujá amarelo representa em torno de 60 a 70\% do peso total do fruto (OLIVEIRA et al., 2002), tornando-se resíduo extremamente expressivo em relação ao volume total processado na indústria, estimado em 40\% da produção nacional (BRUCKNER e PICANÇO, 2001).

A casca do maracujá é constituída basicamente por carboidratos, proteínas e minerais. Dentre os carboidratos da casca, caracterizados essencialmente como fibras alimentares, as pectinas são apontadas como as de maior importância pela capacidade de reduzir o chamado "mau colesterol" (LDL) e aumentar o "bom colesterol" (HDL) (NISHINA e FREEDLAND, 1990; SHUTLER e LOW, 1988; ANDERSON, 1987). As pectinas também estão relacionadas com a redução dos níveis de glicose no sangue, sendo indicadas como auxiliar no tratamento de diabetes (PIEDADE e CANNIATTI-BRAZACA, 2003).

Segundo OLIVEIRA et al. (2002) e LIRA FILHO (1995), a composição da casca do maracujá amarelo permite o seu aproveitamento como matéria-prima vegetal para a elaboração de novos produtos. Nesse aspecto, o estudo de suas propriedades físico-químicas torna-se importante para a exploração de seu potencial como matéria-prima alimentícia.

O padrão de amadurecimento fisiológico do maracujá o caracteriza como fruto climatérico, ou seja, na fase de maturação, o fruto apresenta aumento nas taxas de respiração e de produção de etileno que podem ocorrer na planta ou após a colheita (CHITARRA e CHITARRA, 2005). Durante a fase de maturação, o maracujá amarelo sofre diversas alterações físicas e químicas de síntese e degradação de componentes, dando ao fruto suas características próprias (BRUCKNER e PICANÇO, 2001). Dentre as principais alterações, durante a maturação, estão a degradação de pectina na casca, mudanças de cor da casca e alterações na sua composição de carboidratos, ácidos orgânicos, proteínas e lipídios (AWAD, 1993).

Segundo BRUCKNER e PICANÇO (2001), a mudança de cor da casca é o principal critério indicador do ponto de colheita do maracujá amarelo e reflete as alterações físico-químicas que acompanham o processo de amadurecimento do fruto. Porém, a colheita do maracujá amarelo ocorre pela coleta dos frutos caídos no solo após a sua abscisão natural na planta, ou coletado diretamente dela, em estádio de maturação, quando a casca apresenta cor verde.

Objetivou-se neste trabalho avaliar a interferência do estádio de maturação do maracujá amarelo sobre as características físico-químicas e minerais de sua casca.

\section{MATERIAL E MÉTODOS}

Foram utilizados frutos de maracujá amarelo variedade 'AC275 Maravilha', de segunda safra, e colhidos em pomar comercial em 2007 no município de Santa Helena (PR). A amostra global de maracujá foi constituída de frutos colhidos diretamente da planta com diferentes estádios de maturação, cujas cores das cascas variaram do verde ao amarelo. Posteriormente, os frutos foram transportados em caixas de papelão até o Laboratório de Tecnologia de Alimentos do Centro de Ciências Agrárias da Universidade Estadual do Oeste do Paraná (UNIOESTE), campus de Marechal Cândido Rondon.

Após o recebimento dos frutos no laboratório e de prévia seleção, visando à uniformidade de tamanho e descarte de frutos defeituosos ou enrugados, os mesmos foram higienizados por 
meio de lavagem em água corrente para a retirada de sujidades e secos com papel-toalha. Os maracujás foram classificados segundo a cor da casca conforme a seguinte escala de cores: Estádio 1 - coloração da superfície da casca 100\% verde; Estádio 2 - coloração da superfície da casca verde-amarela (50\% verde e 50\% amarela); Estádio 3 - coloração da superfície da casca $100 \%$ amarela.

Depois de divididos por estádio de maturação, os maracujás foram cortados ao meio com faca de aço inoxidável e separados da casca em relação à polpa (semente e suco) usando-se colher também de aço inoxidável. As partes de cada fruto foram submetidas às determinações de rendimentos de massa por pesagens em balança semianalítica, conforme SILVA et al. (2008).

As análises físico-químicas da casca do maracujá compreenderam matéria seca, cinzas, lipídios totais, proteínas, carboidratos totais e não redutores (PREGNOLATTO e PREGNOLATTO, 1985) e pectinas totais (CARVALHO et al., 2002).

A composição mineral das amostras constou das determinações de fósforo, cálcio, cobre, ferro, manganês, potássio, magnésio e zinco. Para a determinação do fósforo utilizou-se Espectrofotômetro UV-Visível, Marca GBC modelo 916, em comprimento de onda de $420 \mathrm{~nm}$, segundo método de colorimetria do metavanadato de amônio. Os demais minerais foram determinados em espectrômetro de absorção atômica, modalidade chama, Marca GBC, modelo 932 AA (AOAC, 1990). Nesse caso, na construção das curvas de calibração foram utilizadas ampolas de padrões para absorção atômica de 1,0 $\mathrm{g} \mathrm{m} \mathrm{m}^{-1}$, devidamente diluídas com água deionizada (TEDESCO, WOLWEISS e BOHNEM 1995). Na determinação dos minerais utilizou-se a digestão nítrico-perclórica (MALAVOLTA et al., 1997).

Através dos resultados da composição mineral e com base no percentual de Ingestão Diária Recomendada (IDR) na dieta de um adulto (BRASIL, 1998), calculou-se o percentual para ingestão diária de 100 gramas de casca fresca do maracujá amarelo.

Adotou-se delineamento inteiramente ao acaso, com quatro repetições para cada estádio de maturação do maracujá e três frutos por repetição, totalizando 12 unidades experimentais e 36 frutos analisados. Aos resultados foram aplicados Análise de Variância, teste $\mathrm{F}$ e teste Tukey de comparação entre médias $(p<0,05)$ (BANZATTO e KRONKA, 1995).

\section{RESULTADOS E DISCUSSÃO}

Os resultados (Tabela 1) mostraram diminuição significativa $(p<0,05)$ da massa da casca do maracujá amarelo, apenas quando os frutos passaram do segundo para o terceiro estádio de maturação. No entanto, os resultados revelaram a mesma tendência de diminuição da massa fresca da casca e do fruto inteiro com o avanço da maturação do fruto. Destaca-se ainda que o terceiro estádio de maturação correspondeu aos frutos com menor massa fresca da casca e do fruto, verificando-se menor rendimento de casca e maior conteúdo de massa seca.

O aumento no teor de massa seca da casca e a diminuição da massa fresca, especialmente do segundo para o terceiro estádio de maturação, caracterizaram a diminuição no teor de umidade da casca durante a maturação do fruto. Segundo BRUCKNER e PICANÇO (2001), a diminuição de massa fresca na casca do maracujá durante o amadurecimento deve-se principalmente a processos de translocação de água para a polpa.

Em trabalho similar, SILVA et al. (2008) não constataram mudanças significativas no rendimento da casca e na massa fresca total do maracujá amarelo, durante a etapa de maturação fisiológica dos frutos correspondentes ao intervalo de mudança de cor da casca de verde para amarelo. NEGREIROS et al. (2007) verificaram que entre os frutos do maracujá amarelo ocorre enorme variabilidade no rendimento de cascas e na massa fresca dos frutos, também verificada neste trabalho pelos elevados coeficientes de variação nos resultados (Tabela 1 ). 
TABELA 1 - PARÂMETROS FÍSICOS DA CASCA E DO FRUTO INTEIRO DO MARACUJÁ AMARELO PARA OS TRÊS ESTÁDIOS DE MATURAÇÃO

\begin{tabular}{cccccc}
\hline $\begin{array}{c}\text { Estádios de } \\
\text { Maturação }\end{array}$ & \multicolumn{3}{c}{ Casca/fruto } & & Fruto inteiro \\
\cline { 2 - 4 } & Massa fresca, g & Rendimento, \% & Massa seca, \% & & Massa fresca, g \\
\hline Estádio 1 & $153,0 \mathrm{a}$ & $69,4 \mathrm{ab}$ & $6,43 \mathrm{a}$ & & $220,6 \mathrm{a}$ \\
Estádio 2 & $139,0 \mathrm{a}$ & $73,7 \mathrm{a}$ & $7,50 \mathrm{a}$ & \\
Estádio 3 & $107,1 \mathrm{~b}$ & $63,3 \mathrm{~b}$ & $10,50 \mathrm{~b}$ & $188,6 \mathrm{~b}$ \\
\hline CV \% & 23,70 & 21,14 & 5,77 & $169,2 \mathrm{~b}$ \\
\hline
\end{tabular}

Médias seguidas pela mesma letra, na coluna, não diferem ao nível de 5\% de probabilidade pelo teste Tukey.

Estádio 1 - coloração da superfície da casca $100 \%$ verde.

Estádio 2 - coloração da superfície da casca verde-amarelo (50\% verde e 50\% amarelo).

Estádio 3 - coloração da superfície da casca 100\% amarela.

Média de 21 frutos. $\mathrm{CV}=$ coeficiente de variação.

Os resultados (Tabela 2) revelaram diminuição significativa no conteúdo de pectinas totais com a maturação do maracujá amarelo, variando de 28,51 a 20,69 $\mathrm{g} 100 \mathrm{~g}^{-1}$ (redução de 27,43\%). Tais resultados estão de acordo com os relatos de CAMARGO et al. (2007) e LOUSADA JÚNIOR et al. (2007), que verificaram a mesma tendência. Segundo AWAD (1993) e CHITARRA e CHITARRA (2005), a hidrólise e solubilização das pectinas aumentam com o amadurecimento na maioria dos frutos, num processo atribuído à ação de enzimas pectolíticas. Segundo BRUMMEL e LABAVITCH (1997) e HADFIELD e BENNETT (1998), as substâncias pécticas constituem a classe de polissacarídeos da parede celular que sofrem a mais marcante modificação de degradação durante o amadurecimento de frutos como o maracujá.

LOUSADA JÚNIOR et al. (2007) compararam o conteúdo de pectinas de resíduos da agroindústria de abacaxi, acerola, goiaba e melão com o da casca do maracujá amarelo e verificaram que o teor de pectina da casca do maracujá foi inferior apenas à do melão. Constataram-se poucas alterações no conteúdo de carboidratos totais com a maturação do fruto (Tabela 2).

Os valores verificados foram superiores aos encontrados por FERRARI, COLUSSI e AYUB (2004)

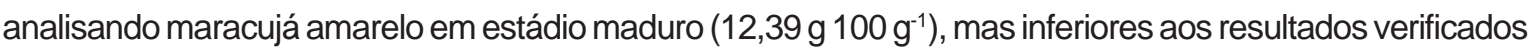

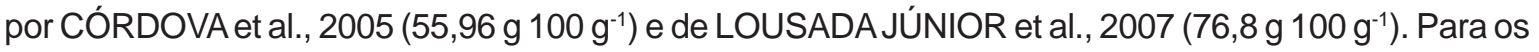
teores de carboidratos redutores, houve diminuição significativa entre o estádio verde e o maduro devido, provavelmente, ao seu consumo pelo metabolismo respiratório do fruto durante a maturação (CHITARRAe CHIATARRA, 2005).

\section{TABELA 2 - COMPOSIÇÃO CENTESIMAL DA CASCA DO MARACUJÁ AMARELO PARA OS TRÊS ESTÁDIOS DE MATURAÇÃO DO FRUTO}

\begin{tabular}{ccccccc}
\hline Estádios de & \multicolumn{5}{c}{ Composição centesimal (g 100 $\mathbf{~ g}^{\mathbf{- 1}}$ da matéria seca) } \\
\cline { 2 - 7 } & $\begin{array}{c}\text { Pectina } \\
\text { total }\end{array}$ & $\begin{array}{c}\text { Carboid ratos } \\
\text { totais }\end{array}$ & $\begin{array}{c}\text { Carboidratos } \\
\text { reduto res }\end{array}$ & $\begin{array}{c}\text { Proteína } \\
\text { bru ta }\end{array}$ & $\begin{array}{c}\text { Lipídios } \\
\text { totais }\end{array}$ & Cinzas \\
\hline Estádio 1 & $28,51 \mathrm{a}$ & $24,39 \mathrm{~b}$ & $19,66 \mathrm{a}$ & $15,60 \mathrm{a}$ & $0,73 \mathrm{a}$ & $11,00 \mathrm{a}$ \\
Estádio 2 & $24,85 \mathrm{~b}$ & $25,77 \mathrm{a}$ & $17,59 \mathrm{~b}$ & $13,16 \mathrm{~b}$ & $0,65 \mathrm{a}$ & $10,38 \mathrm{~b}$ \\
Estádio 3 & $20,69 \mathrm{c}$ & $25,79 \mathrm{a}$ & $16,47 \mathrm{~b}$ & $10,44 \mathrm{c}$ & $0,74 \mathrm{a}$ & $9,11 \mathrm{c}$ \\
\hline CV \% & 4,45 & 1,24 & 3,45 & 4,70 & 3,25 & 2,23 \\
\hline
\end{tabular}

Médias seguidas pela mesma letra, na coluna, não diferem ao nível de $5 \%$ de probabilidade pelo teste Tukey. Estádio 1 - coloração da superfície da casca $100 \%$ verde.

Estádio 2 - coloração da superfície da casca verde-amarelo (50\% verde e 50\% amarelo).

Estádio 3 - coloração da superfície da casca 100\% amarela.

$\mathrm{CV}=$ Coeficiente de variação. 
O teor de proteína bruta da casca do maracujá diminuiu significativamente $(p<0,05)$ com o avanço da maturação do fruto (Tabela 2). Segundo CHITARRA e CHITARRA (2005), as proteínas fazem parte de diversos componentes que sofrem profundas modificações (oxidação biológica) durante o metabolismo respiratório que caracteriza o processo de maturação do maracujá. Em outros trabalhos realizados com casca de maracujá amarelo maduro foram constatados teores de proteína bruta de

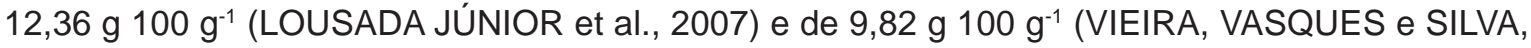
1999), valores esses próximos aos verificados neste trabalho para o terceiro estádio de maturação. LOUSADA JÚNIOR et al. (2007) citaram ainda que as diferentes características de solo e o manejo de adubações (nitrogenadas principalmente) são fatores que podem influenciar o teor de proteína da casca do maracujá amarelo de diferentes cultivos.

Segundo a Tabela 2 não houve efeito dos estádios maturação do fruto sobre o teor de lipídios da casca do maracujá, mas os valores médios observados estão próximos aos teores de 0,51 e

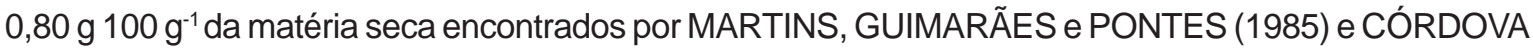
et al. (2005) respectivamente. GONDIM et al. (2005) constataram que a casca do maracujá apresentou teor de lipídios menor do que as cascas de abacate, abacaxi, banana e mamão, evidenciando seu valor calórico relativamente baixo.

Com relação ao teor de cinzas da casca do maracujá (Tabela 2), os resultados revelaram decréscimos significativos com o avanço da maturação do fruto.

Para a composição mineral da casca do maracujá amarelo, a Tabela 3 revela que o avanço da maturação fisiológica do fruto não causou efeito sobre as variáveis, exceto para o cobre que apresentou variação significativa $(p<0,05)$ entre os estádios 1 e 2 . O ferro, o cálcio e o potássio foram os elementos com maior concentração na casca do maracujá amarelo, concordando com os resultados de GONDIM et al. (2005) com exceção para o ferro que mostrou menor concentração na casca. O cobre e o fósforo foram os elementos minerais de menor concentração verificada na casca do maracujá, concordando com LOUSADA JÚNIOR et al. (2007).

\section{TABELA 3 - COMPOSIÇÃO MINERAL DA CASCA DO MARACUJÁ AMARELO PARA OS TRÊS ESTÁDIOS DE MATURAÇÃO}

\begin{tabular}{ccccccccc}
\hline \multirow{2}{*}{$\begin{array}{c}\text { Estádios } \\
\text { de } \\
\text { Maturação }\end{array}$} & \multicolumn{7}{c}{ Composição mineral, mg/100 g da matéria seca } \\
\cline { 2 - 9 } & Fósforo & Potássio & Cálcio & Magnésio & Cobre & Znco & Manganês & Ferro \\
\hline Estádio1 & $0,20 \mathrm{a}$ & $2,38 \mathrm{a}$ & $55,33 \mathrm{a}$ & $1,44 \mathrm{a}$ & $0,24 \mathrm{~b}$ & $11,53 \mathrm{a}$ & $1,21 \mathrm{a}$ & $5,11 \mathrm{a}$ \\
Estádio2 & $0,18 \mathrm{a}$ & $3,64 \mathrm{a}$ & $66,16 \mathrm{a}$ & $1,41 \mathrm{a}$ & $0,00 \mathrm{a}$ & $11,28 \mathrm{a}$ & $1,34 \mathrm{a}$ & $55,48 \mathrm{a}$ \\
Estádio3 & $00,14 \mathrm{a}$ & $2,29 \mathrm{a}$ & $44,95 \mathrm{a}$ & $1,17 \mathrm{a}$ & $0,15 \mathrm{ab}$ & $00,97 \mathrm{a}$ & $1,29 \mathrm{a}$ & $66,37 \mathrm{a}$ \\
\hline CV\% & 50,95 & 22,45 & 27,12 & 25,05 & 53,45 & 53,43 & 42,92 & 53,33 \\
\hline
\end{tabular}

Médias seguidas pela mesma letra, na coluna, não diferem ao nível de 5\% de probabilidade pelo teste de Tukey. Estádio 1 - coloração da superfície da casca 100\% verde.

Estádio 2 - coloração da superfície da casca verde-amarelo (50\% verde e 50\% amarelo). Estádio 3 - coloração da superfície da casca 100\% amarela. $\mathrm{CV}=$ Coeficiente de variação.

Com base nos resultados da Tabela 3 foram determinados os percentuais de ingestão diária recomendada (IDR) para adultos (BRASIL, 1998) de todos os componentes minerais (Tabela 4). Constatou-se que o ferro e o manganês foram os elementos minerais da casca do maracujá amarelo mais expressivos para a dieta de adultos, concordando com GONDIM et al. (2005) que chegaram ao mesmo resultado. 
TABELA 4 - PERCENTUAL DA INGESTÃO DIÁRIA RECOMENDADA (IDR) PARA UM ADULTO AO CONSUMIR A CASCA DE MARACUJÁ AMARELO

\begin{tabular}{ccc}
\hline Minerais & $\begin{array}{c}\text { Ingestão Diária Recomendada } \\
\text { (IDR) }(\mathbf{m g})\end{array}$ & $\begin{array}{c}\text { \% da IDR para 100 g da matéria fresca } \\
\text { da casca do maracujá amarelo }\end{array}$ \\
\hline Zinco & 15,0 & $<1$ \\
Magnésio & 300,0 & $<1$ \\
Potássio & 800,0 & $<1$ \\
Fósforo & 800,0 & $<1$ \\
Cálcio & 800,0 & $<1$ \\
Manganês & 5,0 & 2,56 \\
Ferro & 14,0 & 4,04 \\
Cobre & 3,0 & $<1$ \\
\hline
\end{tabular}

\section{CONCLUSÃO}

O avanço da maturação diminuiu os teores de pectina, proteína bruta e carboidratos redutores.

Considerando o aproveitamento da casca do maracujá amarelo como matéria-prima alimentícia com propriedades funcionais, devido à presença de pectinas, é aconselhável colher o fruto quando a casca apresentar cor verde ou iniciando o amarelecimento sem grandes prejuízos ao seu suco que não se altera muito nas três fases finais de amadurecimento.

O teor de lipídios da casca do maracujá amarelo é baixo, apontando para matéria-prima vegetal de valor calórico relativamente baixo.

Não houve influência dos estádios de maturação do fruto sobre os componentes minerais mensurados. Para a dieta de adultos, a casca do maracujá constitui fonte de manganês e ferro.

\section{ABSTRACT \\ PHYSICOCHEMICAL CHARACTERISTICS OF THE YELLOW PASSION FRUIT SHELL IN DIFFERENT MATURATION STAGES}

This work has as objective to evaluate the interference of the maturation stage of yellow passion fruit on the physical, chemical and minerals characteristics of its shell. Three stages of maturation related to the shell color of the fruit were tested: Stage 1) $100 \%$ green; Stage 2) $50 \% 50 \%$ green and yellow; Stage 3) yellow shell - 100\%. The physical and chemical components measured were: income of the shell; dry matter, ash, total lipids, proteins, total and non-reducing carbohydrates and total pectin. The minerals components determined were: calcium, copper, iron, potassium, magnesium, zinc and phosphorus. The completely random design was used with four replications for each stage of ripeness of fruit. In the results were applied analysis of variance, $F$ test and Tukey test $(p<0.05)$. There was a significant decrease in total pectin content of the shell

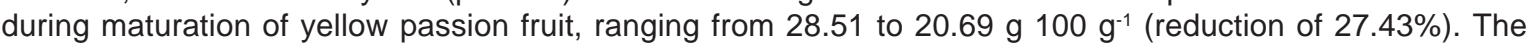
results also showed significant reductions in levels of proteins and reducing carbohydrates. There were no changes in levels of fats and their values showed that the shell of yellow passion fruit has low caloric value. There was no effect of the maturation fruit on the minerals. The iron, calcium and potassium were the elements of higher concentration and cooper and phosphorus of less concentration in the shell. For an adult diet, the shell of the yellow passion fruit was better source of manganese and iron.

KEY-WORDS: Passiflora edulis $f$. flavicarpa; PECTIN; MINERAL; NUTRITIONAL VALUE.

\section{REFERÊNCIAS}

1 AGRIANUAL. Anuário da agricultura brasileira. São Paulo: FNP Consultoria e Comércio, 2007. 
2 ANDERSON, J.W. Dietary fiber, lipids and atherosclerosis. American Journal Cardiovascular, v. 60, p. 17-22, 1987.

3 AOAC. Association of Official Analytical Chemists. Official methods of analysis of AOAC International. 15th ed. Arlington, 1990. v. 1.

4 AWAD, M. Fisiologia pós-colheita de frutos. São Paulo: Nobel, 1993.

5 BANZATTO, D.A.; KRONKA, S.N. Experimentação agrícola. 2. ed. Jaboticabal: FUNEP, 1995.

6 BRASIL. Ministério da Saúde. Secretária de Vigilância Sanitária. Portaria n 33, de 13 de janeiro de 1998 . Adota valores para a ingestão diária recomendada (IDR) de vitaminas, minerais e proteínas. Diário Oficial [da] República Federativa do Brasil, Brasília, (11-E), seção 1, p.5, 1998.

7 BRUCKNER, C.H.; PICANÇO, M.C. (Ed.). Maracujá: tecnologia de produção, pós-colheita, agroindústria, mercado. Porto Alegre: Cinco Continentes, 2001.

8 BRUMMELL, D. A.; LABAVITCH, J.M. Effect of antisense suppression of endopolygalacturonase activity on polyuronide molecular weight in ripening tomato fruit and in fruit homogenates. Plant Physiology, Washington, v.115, p.715725, 1997.

9 CAMARGO, P.; MORAES, M.; SCHEMBEGER, A.; SANTOS, C.P.; SCHEMIN, M.H.C. Rendimento da pectina da casca do maracujá em seus estádios diferentes de maturação: verde, maduro e senescência. In: SEMANA DE TECNOLOGIA EM ALIMENTOS, 5., 2007, Ponta Grossa. Anais... Ponta Grossa: Universidade Tecnológica Federal do Paraná, 2007. v. 2.

10 CARVALHO, H.H.; JOMG, E.V.; BELLÓ, R.M. et al. Alimentos: métodos físicos e químicos de análises. Porto Alegre: UFRGS, 2002.

11 CHITARRA, M.I.F.; CHITARRA, A.B. Pós-colheita de frutos e hortaliças: fisiologia e manuseio. 2. ed. Lavras: ESAL/FAEPE, 2005.

12 CÓRDOVA, V.K.; GAMA, B.T.M.M.T.; WINTER, G.M.C.; NETO, K.G.; FREITAS, S.J.R. Características físico-químicas da casca do maracujá amarelo (passiflora edulis flavicarpa degener) obtida por secagem. B. do CEPPA, Curitiba, v. 23, n. 2, p. 221-230, 2005.

13 FERRARI, R.A.; COLUSSI, F.; AYUB, A.R. Caracterização de subprodutos da industrialização de maracujá aproveitamento das sementes. Revista Brasileira de Fruticultura, Jaboticabal, v. 26, n.1, p.101-102, 2004.

14 GONDIM, M.A.J.; MOURA, V.F.M.; DANTAS, S.A.; MADEIROS, S.L.R.; SANTOS, M.K. Composição centesimal e mineral de cascas de frutas. Ciência e Tecnologia Alimentos, Campinas, v. 25, n. 4, p.825-827, 2005.

15 HADFIELD, K.A.; BENNETT, A.B. Polygalacturonases: many genes in search of a function. Plant Physiology, Washington, v. 117, p. 337-343, 1998.

16 PREGNOLATTO, W.; PREGNOLATTO, N.P. (ed.) Normas analíticas do Instituto Adolfo Lutz: métodos químicos e físicos para análises de alimentos. 3. ed. São Paulo: Instituto Adolfo Lutz, 1985. v. 1.

17 LOUSADA JÚNIOR, E.J.; COSTA. C.M.J.; JOSÉ, M.N.J.; RODRIGUEZ, M.N. Caracterização físico-química de subprodutos obtidos do processamento de frutas tropicais visando seu aproveitamento na alimentação animal. Revista Ciência Agronômica, Fortaleza, v.37, n.1, p.70-76, 2007.

18 LIRA FILHO, J.F. Utilização da casca do maracujá amarelo (Passiflora edulis, f. Flavicarpa, Degener) na produção de geléia. São Paulo 1995. 131 p. Dissertação (Mestrado em Tecnologia de Alimentos). Faculdade de Engenharia de Alimentos, Universidade Estadual de Campinas (Unicamp).

19 MALAVOLTA, E.; VITTI, C.G.; OLIVEIRA, A.S. Avaliação do estado nutricional das plantas: princípios e aplicações - metodologia para análise de elementos em material vegetal. 2. ed. Piracicaba: Potafos, 1997.

20 MARTINS, C.B.: GUIMARÃES, A.C.L.; PONTES, M.A.N. Estudo tecnológico e caracterização física, físico-química e química do maracujá (Passiflora edulis F. Flavicarpa) e seus subprodutos. Fortaleza: Centro de Ciências Agrárias, 1985.

21 NISHINA, P.M.; FREEDLAND, R.A. The effects of dietary fiber feeding on cholesterol metabolism in rats. Journal of Nutrition, v. 120, n. 7, p. 800-805, 1990.

22 NEGREIROS, J.R.S.; ÁLVARES, V.S.; BRUCKNER, C.H.; MORGADO, M.A.D.; CRUZ, C.D. Relação entre características físicas e o rendimento de polpa de maracujá-amarelo. Revista Brasileira de Fruticultura, Jaboticabal, v. 29, n. 3, p. 546-549, 2007.

23 OLIVEIRA, F.L.; NASCIMENTO, F.R.; M; BORGES, V.S.; RIBEIRO, N.C.P.; RUBACK, R.V. Aproveitamento alternativo da casca do maracujá amarelo (Passiflora edulis $f$. flavicarpa) para produção de doce em calda. Ciência e Tecnologia de Alimentos, Campinas, v.22, n.3, p. 259-262, 2002. 
24 PIEDADE, J.; CANNIATTI-BRAZACA, S.G. Comparação entre o efeito do resíduo do abacaxizeiro (caules e folhas) e da pectina cítrica de alta metoxilação no nível de colesterol sanguíneo em ratos. Ciência e Tecnologia de Alimentos, v. 23 , n. 2 , p. $149-156,2003$

25 SILVA, T.V,; RESENDE, E.D.; PEREIRA, S.M.F.; VIANA, A.P.; ROSA, R.C.C.; ALMEIDA, C.L.; VITORAZI, L. Influência dos estádios de maturação sobre as características físicas dos frutos de maracujá-amarelo. Bragantia, Campinas, v. 67 , n. 2, p. 521-525, 2008.

26 SHUTLER, S.M.; LOW, A.G. Influence of baked beans on plasma lipids in pigs fed on a hypercholesterolemic diet. Proceedings of the Nutrition Society, v.47, p.97, 1988.

27 TEDESCO, M.J.; WOLWEISS, S.J.; BOHNEM, H. Análise do solo, plantas e outros materiais. Porto Alegre: UFRGS, 1995. p.188. (Boletim Técnico, 5).

28 VIEIRA, C.V.; VASQUES, H.M.; SILVA, J.F.C. Composição químico-bromatológica e degradabilidade in situ da matéria seca, proteína-bruta e fibra em detergente neutro da casca do fruto de três variedades de maracujá (Passiflora $s p$ ). Revista Brasileira de Zootecnia, v.28, n.5, p.1148-1158. 1999. 